\title{
CHARACTERISTICS OF FIBER TREATMENTS ON TENSILE AND IMPACT STRENGTHS OF PINE RESIN/ARECA HUSK FIBER BIOCOMPOSITES
}

\author{
C.I.P.K Kencanawati, N.P.G Suardana, I.K.G Sugita and I.W.B Suyasa \\ Doctoral Program of Engineering, Faculty of Engineering, \\ Udayana University, Indonesia
}

\begin{abstract}
In this study, alkali treatment was carried out on natural fibers to increase their mechanical strength, change the chemical composition, and clean the fibers of impurities. Areca husk fibers (AHFs) were soaked in an alkaline solution, and dried. Alkali-treated fibers were blended with preheated pine resin, and the tensile and impact strengths of the pine resin/AHFs biocomposites were evaluated. The fibers treatment, the tensile strength increased by about $11 \%$ and icreased by about $33 \%$ compared with untreated fiber biocomposites. Alkali treatment also increased The value of the Young's modulus of the fibers by about 9.2\%. The impact strength of the pine resin increased by nearly $42 \%$ from the presence of $10 \%$ by weight AHFc content. For the pine resin/AHFs biocomposites, the impact strength increased $24 \%$ compared with untreated AHFs. The mercerization increased the adhesion of the fiber-matrix interface, enabling efficient transfer of tension from the matrix to the AHFs.By the SEM, increased adhesion bonding between the matrix and the fibers was also detected. This is significant, considering that tensile and impact strengths are some of the most important mechanical properties of a composite material thet are affeted by the bonding force between the matrix and the fibers.
\end{abstract}

Keywords: alkaline, areca husk fibers, pine resin.

Cite this Article: C.I.P.K Kencanawati, N.P.G Suardana, I.K.G Sugita and I.W.B Suyasa, Characteristics of Fiber Treatments on Tensile and Impact Strengths of Pine Resin/Areca Husk Fiber Biocomposites. International Journal of Civil Engineering and Technology 11(1), 2020, 86-93.

http://iaeme.com/Home/issue/IJCIET?Volume=11\&Issue=1

\section{INTRODUCTION}

Utilization of natural fibers in the science of materials has been widely developed [1,2], especially natural fibers derived from agricultural waste that has been not utilized to the fullest. Along with the increasing public awareness of environmental pollution and the use of renewable natural materials various agricultural waste began to be developed [3]. 
Given all this time in the material use of synthetic fiber has been done because of several advantages of synthetic fibers. But on the one hand synthetic fibers have serious flaws in terms of biodegradability, high initial processing cost, recycling, energy consumption, machine abrasion and health hazards [4,5].

One type of agricultural waste that has potential as a biocomposite reinforcement is areca husk fibers (AHFs) [6,7], which are quite abundant, have a low density, are renewable, can naturally decompose, and have good mechanical properties. Areca trees will bear fruit depending on the soil conditions, and the average areca tree in Indonesia after the age of 5-8 years produces fruits in the shape of a round egg with lengths between 3.5 and $7 \mathrm{~cm}$. A hard, fibrous fruiting wall covers the endosperm and the husk weighs about $60 \%-80 \%$ of the total weight of the fruit. The fiber length is $5-6 \mathrm{~cm}$ on average and the diameter is $0.3-0.5 \mathrm{~mm}$ [8]. In general, the chemical composition of the areca nut consists of lignocellulose, which comprises cellulose, hemicellulose, lignin, and other components [9]. Lignocellulose is an organic material contained in plants and is hydrophilic because it contains many hydroxyl groups. Since the composite matrix is generally hydrophobic, this often leads to low composite material interface bonds. Therefore, it is necessary to apply certain treatments to natural fibers that are to be used as reinforcement in composites to improve the binding ability with the matrix, which can also affect the chemical composition of the fiber and fiber structure and reduce natural fiber moisture. A common chemical treatment is alkali $(\mathrm{NaOH})$ treatment, which is one method to increase cellulose content through hemicellulose and lignin removal [10]. As the strength and stiffness of plant fibers depend on the cellulose content, increased cellulosic content is a key factor for improving fiber properties. Alkali treatment can purify and repair the fiber surface to lower surface tension and increase the interface bonding of the fibers and matrix [11]. The alkalization process brings up cellulose and removes impurities on the surface of natural fibers, such as lignin and pectin, to improve the mechanical properties af fibers $[12,13]$.

The matrix used in this study as a composite material does not damage the environment. Therefore, the proposed biocomposite is environmentally friendly too. Using areca husk fibers and pine resin will help to save resources. Pine resin has hydrophobic characteristics and is soluble in neutral solvents or nonpolar organic solvents (ethyl ether, hexane, and oil solvents) [14-16]. Colophony is used as a mixing agent in sizing agents, printing ink factories, varnishes, and adhesives. In $[17,18]$, colophony esters of pine resin processing were reported to be widely used in the printing ink, coating, and adhesive industries. In [19], the used of colophony as a glue showed that it is fractal is 1.3319 , which means that colophony has a level of regularity of grains/aggregates that is less regular, making it easier for other substances to be absorbed into the grain structure; in other words, it has good adhesiveness. Based on the characteristics of the properties of colophony, it is possible to use it as a matrix in a composite, given that the potential for the development of natural composites is very high [20]. Considering the importance of surface treatment as an initial step in the process of making natural-fiber-reinforced biocomposites, we investigated the effect of alkali treatment of fibers $(\mathrm{NaOH})$ on the tensile strength, impact strength, and morphology of natural fibers in a pine resin/areca husk biocomposites.

\section{MATERIALS AND METHODS}

Pine resin $\left(1.1 \mathrm{~g} / \mathrm{cm}^{3}\right)$ was obtained from $\mathrm{KPH}$ East Bali, and areca husks were from Payangan, Gianyar, Bali. The fiber was selected from the ripe areca, as shown in Figure 1. These areca husk fibers had a high cellulose content (54\%) and a low lignin content $(21 \%)$ [21]. 


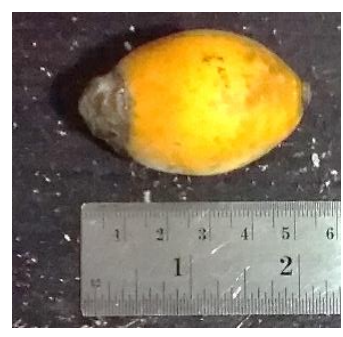

(a)

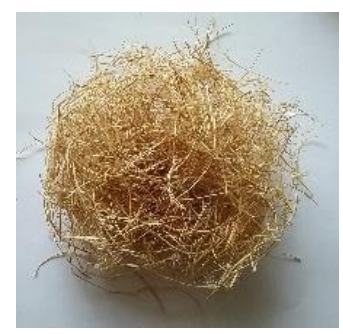

(b)

Figure 1. Natural fibers (a) Areca fruit and (b) areca husk fibers.

\subsection{Retting}

The process of retting the fibers was done mechanically by separating the fruit core from the husk, and the husk of the areca was cleaned in a water medium until the areca husk fibers detached from the connective tissue. Furthermore, the fiber was immersed in water for about one week. It was then removed, cleaned, and allowed to air-dry. [22].

\subsection{Pine Resin Preparation}

Pine resin was heated at a temperature of $170{ }^{\circ} \mathrm{C} 90 \mathrm{~min}$, with a gagnetic stirrer speed of 400 rpm until golden-colored.

\subsection{Tensile Properties}

The spesimens of tensile tests were based on ASTM D638. The tests were under taken by use of an universal testing machine to determine the tensile strength, tensile modulus, and elengation at break at room temperature. The testing conditions used were load cells of $0.5 \mathrm{kN}$ with a crosshead speed of $2 \mathrm{~mm} / \mathrm{min}$. The reported value are the average of at least five meansurements.

\subsection{Impact Strength Measurement}

Impact tests were performed with a impact machine according to ASTM D256, with notched Izod impact strength. Five spesimens were measured for each sample.

\subsection{Morphological Characterization by SEM}

Pine resin/areca husk fiber biocomposites were mounted into specimen stubs using doublesided adhesive.

\section{RESULTS}

\subsection{Tensile Test Results}

Tensile strength is defined here as the force per unit area $\left(\mathrm{N} / \mathrm{mm}^{2}\right.$ or $\left.\mathrm{MPa}\right)$ required to break the biocomposite material. This test was performed until complete failure or breaking. The effect of chemical treatment and volume fraction on the tensile strength of areca husk fiber reinforced pine resin biocomposites with $5 \%, 10 \%, 15 \%$, and $20 \%$ fiber loads is reported in Table 1. 
Table 1. Mechanical properties determined by tensile test (TS, tensile strength; $\varepsilon$, elengation; E, modulus)

\begin{tabular}{lccc}
\hline \multicolumn{1}{c}{ Biocomposite } & TS (MPa) & $\boldsymbol{\varepsilon}(\mathbf{\%})$ & E (GPa) \\
\hline Pine Resin (PR) (S-1) & 0.08 & 0.71 & 0.01 \\
AHF-NT (S-2) & 148.32 & 20.05 & 2.33 \\
AHF-T (S-3) & 164.86 & 17.47 & 2.89 \\
PR/AHF-NT (10:90) (S-4) & 4.25 & 2.32 & 0.08 \\
PR/AHF-T (5:95) (S-5) & 3.87 & 1.08 & 0.07 \\
PR/AHF-T (10:90) (S-6) & 5.65 & 1.72 & 0.09 \\
PR/AHF-T (15:85) (S-7) & 4.90 & 1.88 & 0.11 \\
PR/AHF-T (20:80) (S-8) & 4.27 & 1.97 & 0.16 \\
\hline
\end{tabular}

Table 1 shows the mechanical properties (TS, $\varepsilon$, and E) of biocomposites containing different charcoal treatment fibers. The biocomposite tensile strength was strongly influenced by the adhesiveness of the fiber and matrix, where chemical treatment with $\mathrm{NaOH}$ affected the tensile strength and tensile modulus (E). The $\mathrm{NaOH}$ treatment increased the tensile strength of the biocomposites significantly by about $33 \%$ compare with biocomposites made with untreated fibers.

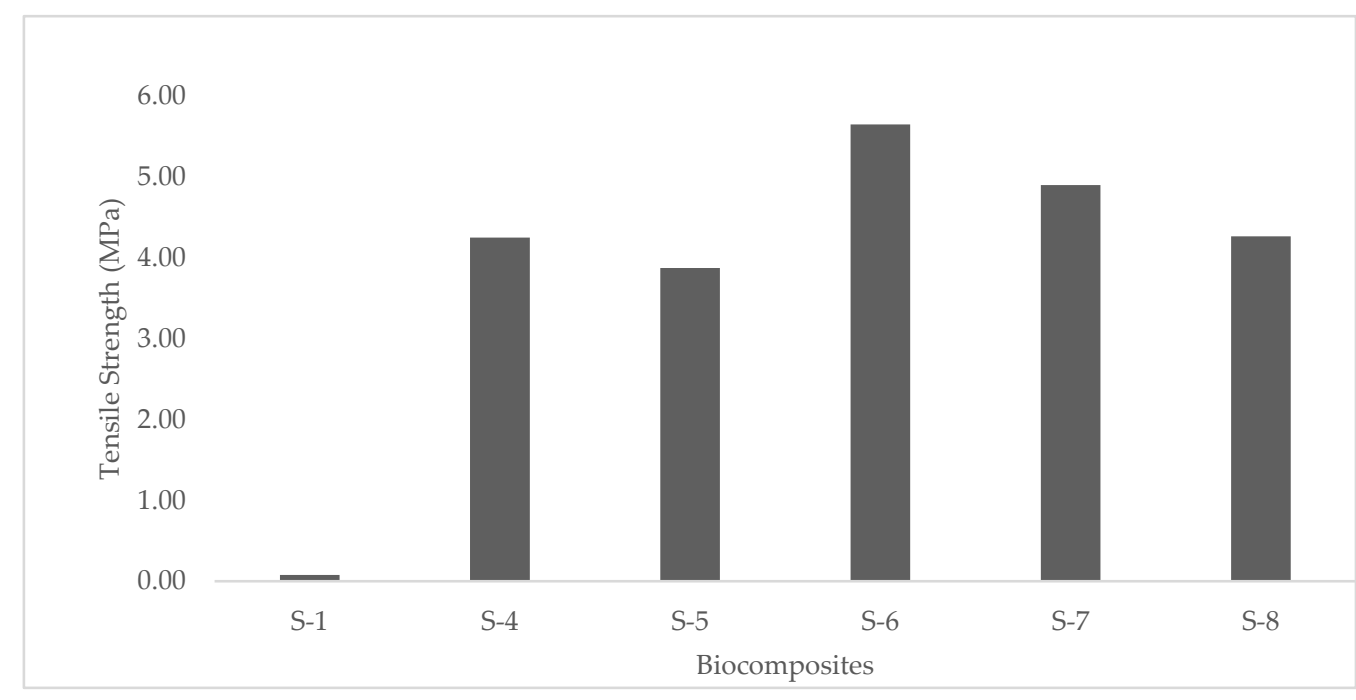

Figure 2. Tensile strength of areca husk fiber after treatments

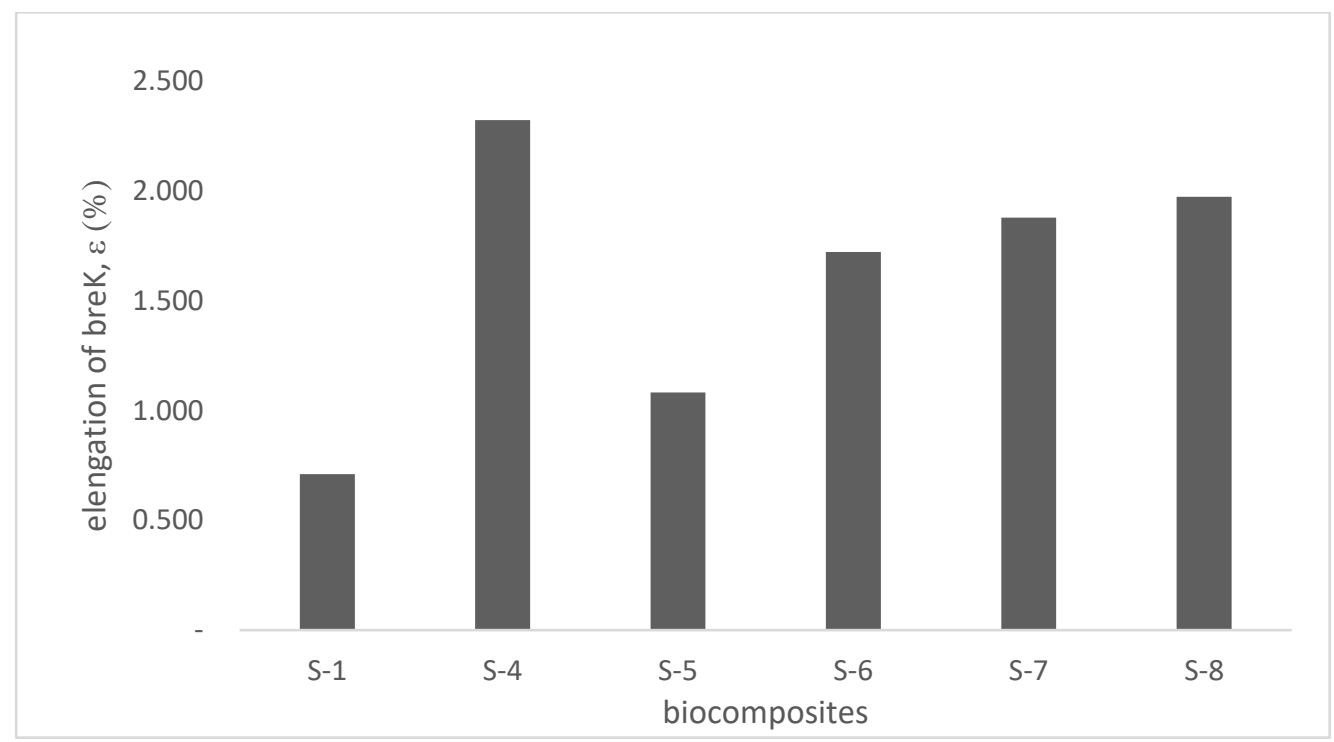

Figure 3. Elengation of areca husk fiber treatments. 
Characteristics of Fiber Treatments on Tensile and Impact Strengths of Pine Resin/Areca Husk Fiber Biocomposites

\subsection{Impact Test Results}

Table 2. Experimental impact strength of the biocomposite samples

\begin{tabular}{lcccccc}
\hline \multicolumn{1}{c}{ Composite } & T1 & T2 & T3 & T4 & T5 & AVERAGE \\
\hline Pine Resin (PR) & 0.0332 & 0.0324 & 0.0384 & 0.0401 & 0.0495 & 0.0387 \\
PR/AHF-NT & 0.0411 & 0.0421 & 0.0498 & 0.0403 & 0.0488 & 0.0444 \\
PR/AHF-T (5:95) & 0.0466 & 0.0445 & 0.0474 & 0.0504 & 0.0483 & 0.0474 \\
PR/AHF-T (10:90) & 0.0600 & 0.0534 & 0.0515 & 0.0519 & 0.0577 & 0.0549 \\
PR/AHF-T (15:85) & 0.0486 & 0.0436 & 0.0493 & 0.0546 & 0.0492 & 0.0490 \\
PR/AHF-T (20:80) & 0.0421 & 0.0436 & 0.0525 & 0.0467 & 0.0449 & 0.0460 \\
\hline
\end{tabular}

During the impact testing process the spesimen must be loaded in the testing machine and be subjected to pendulum swings until it fracturer or breaks. Using the impact test, the energy needed to break the material can be easily measured to determine the tougness of the material and the yield strength. The effect of strain rate on the fracture and ductility of the material can be analyzed using the impact test.

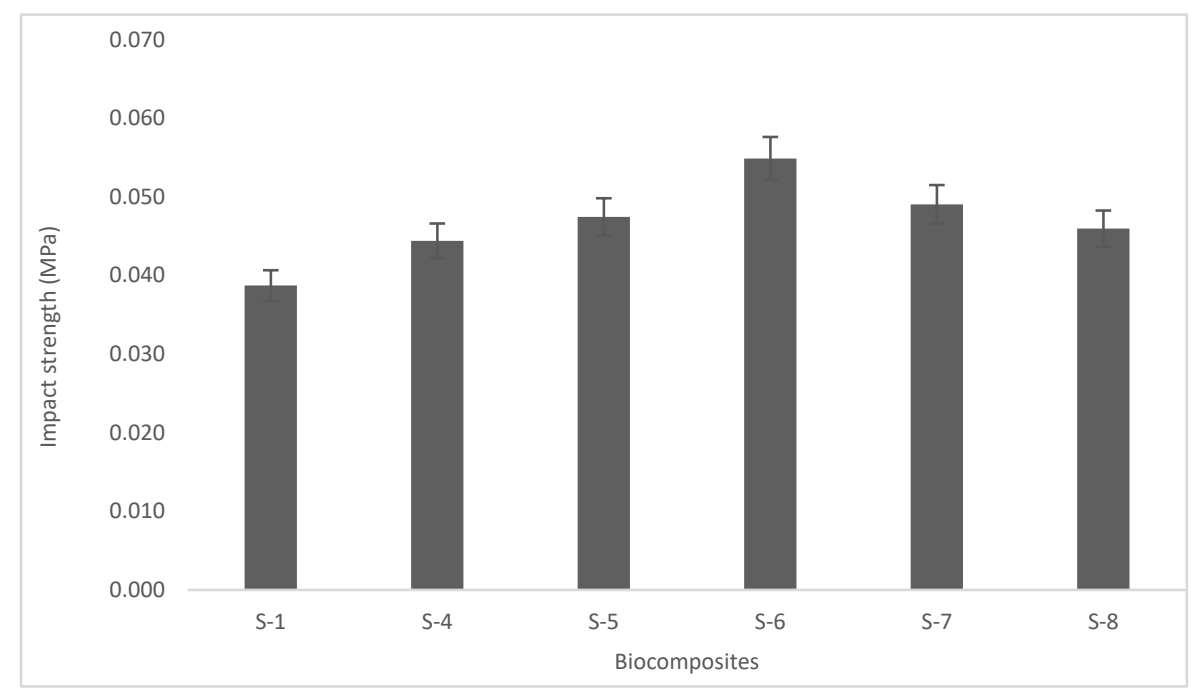

Figure 4. Impact strength comparison of pine resin, fibers and pine resin/areca husk fiber biocomposite.

\subsection{Morphology of Areca Husk Fibers}

After the process of retting, the areca husk fibers turned a brownish color, as shown in Figure 5 , and had a density value without alkali treatment of $0.633 \mathrm{~g} / \mathrm{cm}^{3}$.
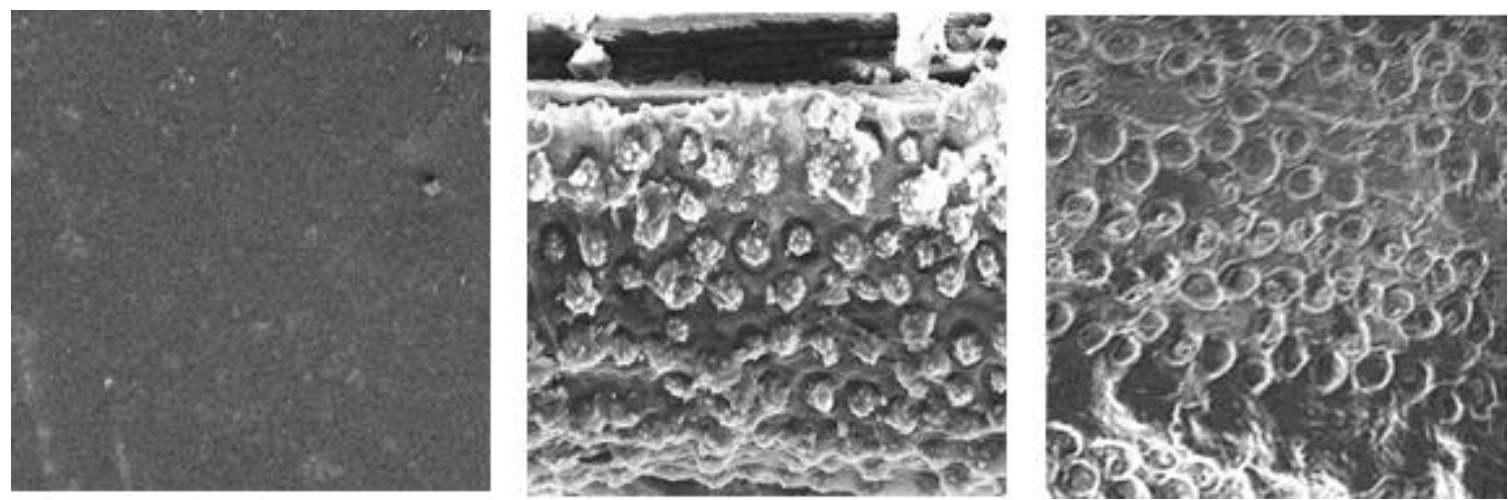

Figure 5. Morphology of samples (a) pine resin and (b) AHF before treatment. (c) AHF after treatment observed with SEM 

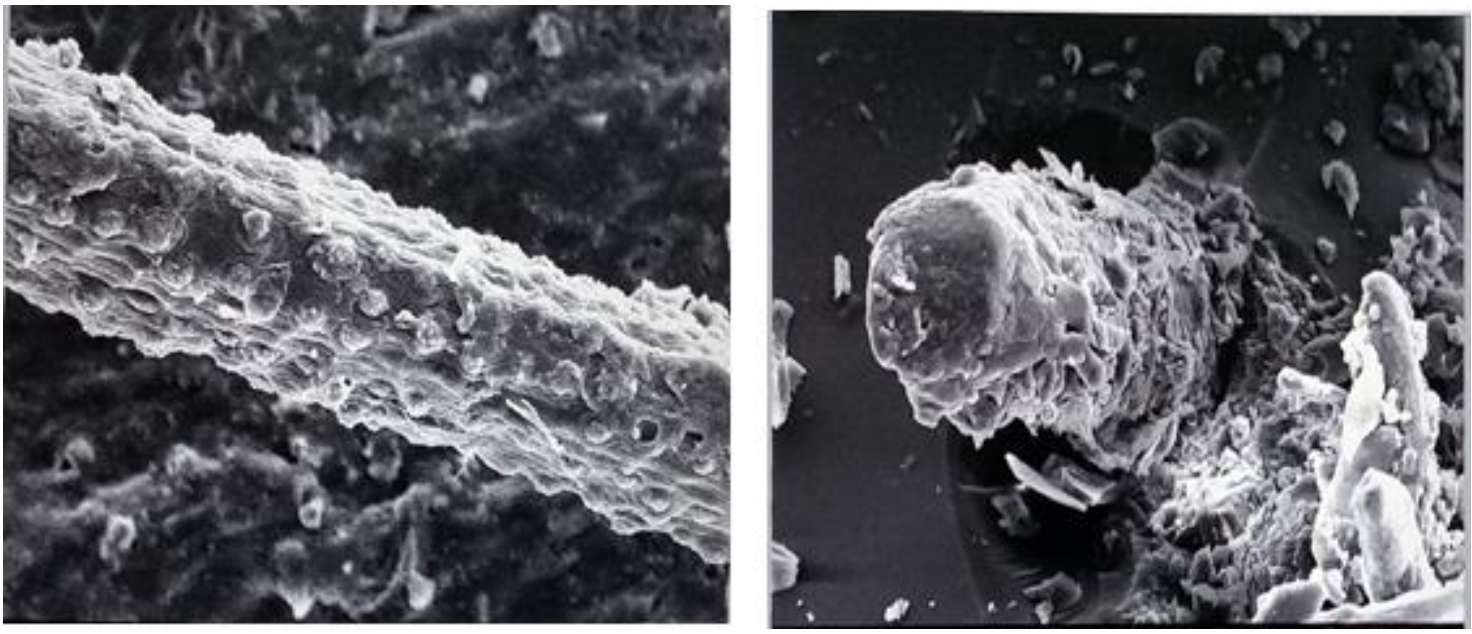

Figure 6. Biocomposite morphology of pine resin/areca husk fibers without alkali treatment observed with SEM: (a) 400× and (b) 500× magnification.
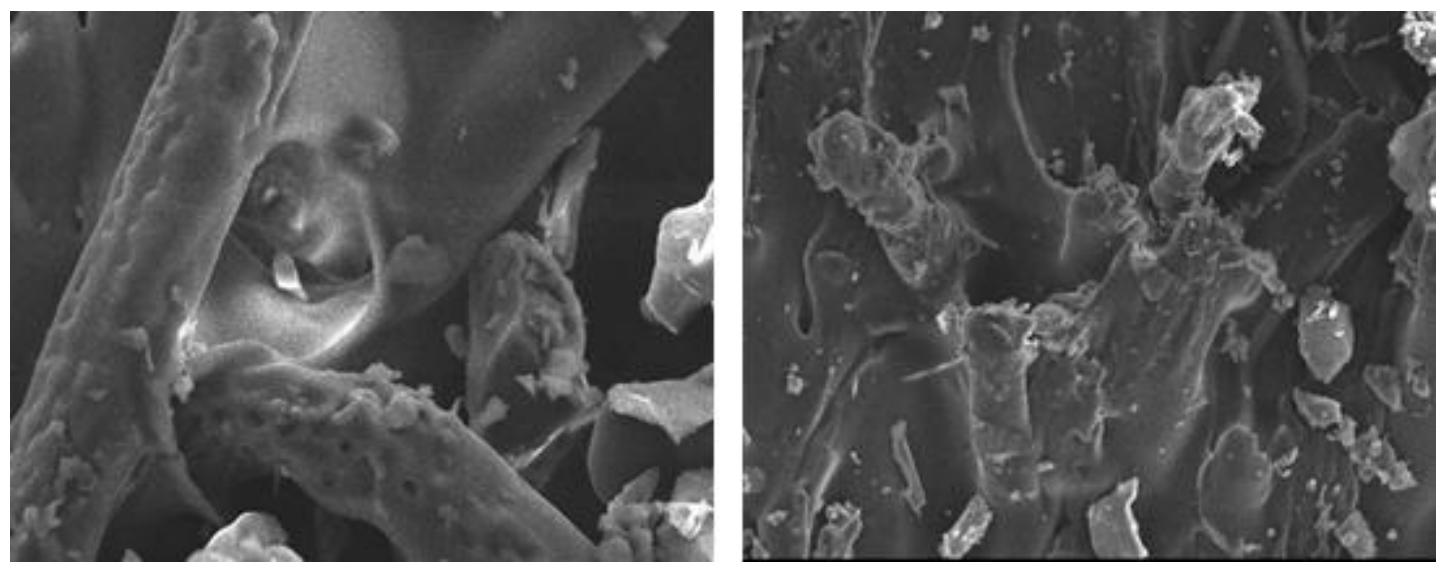

Figure 7. Morphology of pine resin/areca husk fiber biocomposite with alkali treatment observed with SEM: (a) $400 \times$ and (b) $500 \times$ magnification.

\section{DISCUSSION}

\subsection{Tensile Strength}

The tensile strength comparison of the different combinations of areca husk fiber/pine resin biocomposites is presented in Fig.2. The figure shows that the 10\% areca husk fiber and $90 \%$ pine resin biocomposites performed better than the other composite combinations tested. This indicates thet the immersion conditions improved the adhesion of the fiber-matrix inteface and the wettability, allowing the efficient transfer of stress between matrix and fiber. Also as reported by Mohanty et al. [2001], alkali treatment reduces the fiber diameter and thereby improves the aspect ratio and the mechanical characteristic of the composite.

Figure 3 shows that the elengation of break $(\varepsilon)$ of the biocomposites was affected by different treatment and fiber volume fractions compared with the biocomposites made with untreated fibers. However, the addition of treatment fibers resulted in an increase in the value of $\varepsilon$ compared the fiberless pine resin. As shown in Fig.4, the elengation of break $(\varepsilon)$ of the treated fibers decreased by $35 \%$ compared with the untreated fibers.

\subsection{Impact Strength}

Figure 4 shows the impact strength of the biocomposite. The surface treatment increased the impact strength of the biocomposite. The impact strength of the treated biocomposite surface 
was higher then the pine resin matrix itself. The impact strength of the pine resin increased by nearly $42 \%$ with the presence of $10 \%$ by weight AHF content. For the pine resin/areca husk fiber biocomposites, adhesion of the fiber matrix interface from the alkali treatment, which removed natural and artificial impurities and resulted in a rough surface topography [12].

\subsection{Morphology of Areca Husk Fibers}

The morphology of the tensile surface of the untreated fibers and alkali treated pine resin/areca husk fibers biocomposites is shown in Figure 6, which illustrates some of the remaining holes after the fibers were pulled out of the matrix, some of which appear to have been broken and damage. A visible gap can be found between the fiber and pine resin matrix in Figure 6, indicating poor interfacial adhesion. However, the gap virtually disappeared in the case of fibers treated with $\mathrm{NaOH}$ (Figure 7), proving there was good compatibility in the pine resin/areca husk biocomposites which led to the enhancement of the interface and mechanical properties of the biocomposite. Untreated fibers could be easily pulled out of the interface area with poor compatibility, resulting in the rapid partial collapse of the pine resin. However, alkali-treated fibers had good adhesion with the pine resin matrix, which could effectively spread and transfer stress, leading to improvements in the mechanical properties of the biodegradable pine resin/areca husk fiber biocomposites. Consequently, the results indicate thet alkali treatment of fibers is required to improve the adhesion of fiber-matrix interface before biocomposite processing.

\section{CONCLUSIONS}

In this study, pine resin/areca husk fiber biocomposites with different fiber contents were developed. The effect of alkali treatment on the interface and mechanical properties of the pine resin/areca husk fiber biocomposites was studied, and the following conclusions can be drawn:

- The mechanical properties of the studied AHFs were measured and evaluated. Alkali treatment of AHFs increased the tensile strength by $11 \%$ compared with AHFs without treatment.

- The alkali treatment of AHFs increased the surface roughness of the fibers, causing a mutual mechanical increase between the fibers and the pine resin matrix in the composite.

- The tensile strength of the biocomposite increased with treatment by up to $25 \%$, but it was more than $33 \%$ and the impact strength increased $24 \%$ for the $10 \%$ AHF volume fraction.

- The study also showed that the alkalization process can modify the fiber surface, which significantly contributes to improving the interface properties of the biocomposite.

\section{REFERENCES}

[1] L. Mohammed, M. N. M. Ansari, G. Pua, M. Jawaid, and M. S. Islam, "A Review on Natural Fiber Reinforced Polymer Composite and Its Applications," vol. 2015, 2015.

[2] D. Chandramohan and K. Marimuthu, "A Review On Natural Fibers," vol. 8, no. August, pp. 194-206, 2011.

[3] K. Senthilkumar et al., "Mechanical properties evaluation of sisal fibre reinforced polymer composites: A review," Constr. Build. Mater., vol. 174, pp. 713-729, 2018.

[4] A. K. Mohanty, L. T. Drzal, and F. Group, Natural Fibers, Biopolymers, and Biocomposites. 2005.

[5] M. Brodhagen, M. Peyron, C. Miles, and D. A. Inglis, "Biodegradable plastic agricultural mulches and key features of microbial degradation," Applied Microbiology and Biotechnology, vol. 99, no. 3. pp. 1039-1056, 2014. 
[6] L. Yusriah, S. M. Sapuan, E. S. Zainudin, and M. Mariatti, "Exploring the Potential of Betel Nut Husk Fiber as Reinforcement in Polymer Composites: Effect of Fiber Maturity," Procedia Chem., vol. 4, pp. 87-94, 2012.

[7] CIPK Kencanawati, N. P. G. Suardana, I. K. G. Sugita, and I. W. B. Suyasa, “A study on biocomposite from local balinese areca catechu 1. husk fibers as reinforced material," IOP Conf. Ser. Mater. Sci. Eng., vol. 201, no. 1, 2017.

[8] CIPK Kencanawati, N. P. G. Suardana, I. K. G. Sugita, and I. W. B. Suyasa, "Characterization and exploring of local balinese areca husk fibers as reinforced material biocomposite," vol. 201, no. Ickem, 2017.

[9] E. Jayamani, S. Hamdan, M. R. Rahman, and M. K. Bin Bakri, "Investigation of fiber surface treatment on mechanical, acoustical and thermal properties of betelnut fiber polyester composites," Procedia Eng., vol. 97, pp. 545-554, 2014.

[10] G. C. Mohan Kumar, "A Study of Short Areca Fiber Reinforced PF Composites," Proc. World Congr. Eng. 2008, vol. II, pp. 3-8, 2008.

[11] S. Huo, M. A. Fuqua, V. S. Chevali, and C. A. Ulven, "Effects of Natural Fiber Surface Treatments and Matrix Modification on Mechanical Properties of Their Composites," SAE Intenational, no. 2, pp. 1-10, 2010.

[12] H. Deka, M. Misra, and A. Mohanty, "Renewable resource based 'all green composites' from kenaf biofiber and poly(furfuryl alcohol) bioresin," Ind. Crops Prod., vol. 41, no. 1, pp. 94-101, 2013.

[13] B. Djatmiko and A. P. Widjaja, "Minyak dan lemak," Dep. THP IPB Bogor, 1973.

[14] Wang et al., "Combining renewable gum rosin and lignin: Towards hydrophobic polymer composites by controlled polymerization," J. Polym. Sci. Part A Polym. Chem., vol. 49, no. 17, pp. 3728-3738, 2011.

[15] B. Wiyono, P. Hastoeti, and E. Kusmiyati, "Effect of storage on the quality of the processed product of pine resin from West Sumatra," Bul. Penelit. Has. Hutan, 2003.

[16] S. Zhaobang, "Production and Standards for Chemical Non-Wood Forest Products in China," vol. 62, no. 6, 1995.

[17] S. Oancea, "Fractal Analysis on Chemical Degradation of Natural Resins Protector Film," vol. 4, no. 3, pp. 63-69, 2008.

[18] CIPK Kencanawati, N. P. G. Suardana, I. K. G. Sugita, and I. W. B. Suyasa, "Characterization physical, mechanical, thermal and morphological properties of Colophony," vol. 2, no. 2, pp. 17-19, 2017.

[19] D. Sampathkumar, R. Punyamurthy, B. Bennehalli, and S. C. Venkateshappa, "Effect Of Esterification On Moisture Absorption Of Single Areca Fiber," vol. 4, no. 4, pp. 227-229, 2012.

[20] M. F. Rosa et al., "Effect of fiber treatments on tensile and thermal properties of starch/ethylene vinyl alcohol copolymers/coir biocomposites," Bioresour. Technol., vol. 100, no. 21, pp. 5196-5202, 2009.

[21] D. Sampathkumar, R. Punyamurthy, B. Bennehalli, and S. C. Venkateshappa, "Effect Of Esterification On Moisture Absorption Of Single Areca Fiber," vol. 4, no. 4, pp. 227-229, 2012.

[22] M. F. Rosa et al., "Effect of fiber treatments on tensile and thermal properties of starch/ethylene vinyl alcohol copolymers/coir biocomposites," Bioresour. Technol., vol. 100, no. 21, pp. 5196-5202, 2009. 